Article

\title{
Relationship between Flowability, Entrapped Air Content and Strength of UHPC Mixtures Containing Different Dosage of Steel Fiber
}

\author{
Rui Wang ${ }^{1}$ and Xiaojian Gao ${ }^{1,2, *}$ \\ School of Civil Engineering, Harbin Institute of Technology, Harbin 150090, China; wangrui8703@hit.edu.cn \\ 2 Key Lab of Structures Dynamic Behavior and Control (Harbin Institute of Technology), \\ Ministry of Education, Harbin 150090, China \\ * Correspondence: gaoxj@hit.edu.cn; Tel./Fax: +86-451-8628-1118
}

Academic Editor: Stefano Invernizzi

Received: 4 July 2016; Accepted: 25 July 2016; Published: 29 July 2016

\begin{abstract}
This study investigated the effects of different fiber contents by volume $(0 \%, 1 \%, 2 \%$, and $3 \%$ ) on flowability, entrapped air content, and compressive and flexural strength of ultra high performance concrete (UHPC). Four water-to-binder ratios $(0.18,0.20,0.22,0.24)$ were used and four different dosages of superplasticizer were introduced for preparing each water-to-binder ratio mixture. The experimental results reveal that the increased content of fiber decreases the flowability and entrapped air content of fresh UHPC mixtures. The compressive strength of UHPC increased with a greater addition of steel fiber, from $1 \%$ to $3 \%$. The flexural strength was increased slightly by the addition of $1 \%$ steel fiber and increased remarkably with the addition of $2 \%$ and $3 \%$ steel fiber. For every water-to-binder ratio mixture, with and without steel fiber, a good linear relationship can be found between compressive strength and entrapped air content. Therefore, it is suggested that lowering the entrapped air provides a significant contribution to increasing compressive strength of UHPC containing higher steel fibers.
\end{abstract}

Keywords: UHPC; steel fiber; flowability; entrapped air content; mechanical properties

\section{Introduction}

As a new cement-based material, ultra high performance (UHPC) has gained interest around the world since it was introduced in the early 1990s. Ultra high performance concrete (UHPC) can show compressive strength from 150 to $810 \mathrm{MPa}$ [1], approximately 3-16 times that of conventional concrete. Due to the improved mechanical strength, impact resistance, fatigue resistance, and its excellent durability [2-4], UHPC is also regarded as a construction material for energy saving, material saving, and low carbon emission. Presently, applications of UHPC have been reported in Europe, North America, Australia, Asia and New Zealand [5].

One of the key factors in producing UHPC is to improve the particle packing density of its cementitious matrix. Therefore, many studies have been conducted on the selection of raw materials, such as cement types and fineness, silica fume, fly ash, metakaolin, rice husk ash, nanoparticles and different type of fine aggregate [5-9], optimal mixing proportions, and curing conditions [10]. The addition of fiber can improve the flexural properties of UHPC, and also leads to the transformation from brittle failure to ductile failure [11]. The fibers used in concrete include carbon, steel, polypropylene and glass fibers, and most researchers have paid attention to the steel fiber. It was reported that the tensile strength of UHPC linearly increased with increased steel fiber volume ratio, from $0 \%$ to $5 \%$ [12]. UHPC mixtures incorporating short steel fibers exhibited enhanced flexural properties compared to those of mixtures with a similar volume of longer steel fibers [13]. The shape and distribution of steel 
fiber also have a great influence on the mechanical properties of hardened UHPC [14,15]. Although a number of researchers have studied the influence of steel-fiber addition on mechanical properties, limited information is available about the effects of steel fiber content on the fresh properties of UHPC with variable $w / b$ and superplasticizer [16], and there is little knowledge about the relationships of flowability, entrapped air content and strength of UHPC containing steel fibers.

The objective of this research is to investigate the effects of four fiber contents $(0 \%, 1 \%, 2 \%, 3 \%)$ and four water-to-binder ratios $(0.18,0.20,0.22,0.24)$ with different dosages of superplasticizer on flowability, entrapped air content, compressive and flexural strength of UHPC. Statistical analyses of the experimental data were carried out, and the relationship between flowability and air content, and the relationship between air content and compressive strength, were presented.

\section{Experimental Section}

\subsection{Raw Materials}

Ordinary Portland cement with strength grade of 42.5, complying with the Chinese Standard GB175-2007 [17], was used. Silica fume (SF) was used as a fine mineral admixture with a specific surface area of $1.5 \times 10^{5} \mathrm{~cm}^{2} / \mathrm{g}$ and a $\mathrm{SiO}_{2}$ content of more than $96 \%$, according to the Chinese Standard GB/T 21236-2007 [18]. The chemical compositions of cement and silica fume are given in Table 1.

Table 1. Chemical composition of cementitious materials.

\begin{tabular}{ccc}
\hline Constituent & Cement (wt. \%) & Silica Fume (wt. \%) \\
\hline $\mathrm{CaO}$ & 64.48 & 1.5 \\
$\mathrm{SiO}_{2}$ & 21.41 & 96.3 \\
$\mathrm{Al}_{2} \mathrm{O}_{3}$ & 5.43 & 0.54 \\
$\mathrm{Fe}_{2} \mathrm{O}_{3}$ & 3.51 & 0.64 \\
$\mathrm{MgO}$ & 1.47 & 0.16 \\
Loss on ignition & 2.54 & 1.43 \\
\hline
\end{tabular}

Two types of quartz sand produced by Harbin Jinghua Water Treatment Material Company (Harbin, China) were used as aggregates, as shown in Table 2. A mixture of $80 \%$ coarse quartz sand and $20 \%$ fine quartz sand was used for preparing all the UHPC mixtures.

Table 2. Physical and mechanical performances of quartz sand.

\begin{tabular}{cccccc}
\hline \multirow{2}{*}{$\begin{array}{c}\text { Quartz Sand } \\
\text { Type }\end{array}$} & $\begin{array}{c}\text { Particle Size } \\
(\mu \mathrm{m})\end{array}$ & \multicolumn{2}{c}{ Constituent (wt. \%) } & Apparent Density $\left(\mathrm{g} / \mathrm{cm}^{3}\right)$ & Bulk Density $\left(\mathrm{g} / \mathrm{cm}^{3}\right)$ \\
\cline { 2 - 4 } & $\mathbf{S i O}_{2}$ & $\mathbf{F e}_{2} \mathbf{O}_{3}$ & & \\
\hline Coarse & $360-600$ & $\geqslant 99.6$ & $\leqslant 0.02$ & 2.65 & 1.405 \\
Fine & $180-360$ & $\geqslant 99.6$ & $\leqslant 0.02$ & 2.65 & 1.329 \\
\hline
\end{tabular}

A polycarboxylate-based superplasticizer (SP) from Harbin Qiangshi Company (Harbin, China) was used. It has a water-reducing efficiency higher than $30 \%$ and a solid content of about $40 \%$. The steel fibers (as shown in Figure 1) used in this study are copper-coated, smooth fibers with a tensile strength of $2850 \mathrm{MPa}$. Each fiber is $13 \mathrm{~mm}$ long with a diameter of $0.2 \mathrm{~mm}$. 


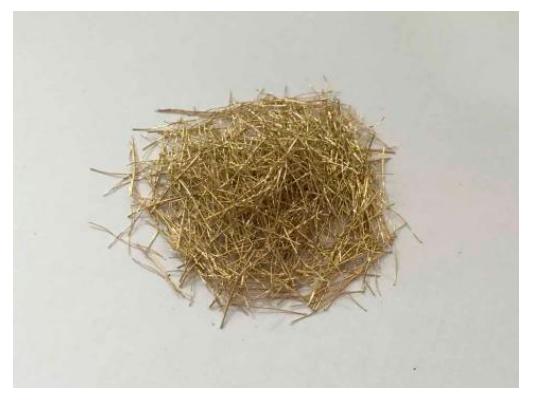

Figure 1. Example of the steel fibers used in this study.

\subsection{Mixing Proportions of UHPC Mixtures}

The ratio of cement:silica fume:quartz sand was kept at the value of 1:0.3:1.1 for all the mixtures, as shown in Table 3. All the mixtures can be divided into four series, with different water-to-binder (cement + silica fume) ratios of $0.18,0.20,0.22$ and 0.24 . In every series, with the same water-to-binder ratio, varying dosages of superplasticizer by mass of cementitious materials were added to obtain different flowabilities for the UHPC mixtures, and different steel fiber contents of $0 \%, 1 \%, 2 \%$, and $3 \%$ by volume of mixture were used at every superplasticizer dosage level. Therefore, a total of 64 mixtures were manufactured in this study.

Table 3. Mix proportion of ultra high performance concrete (UHPC).

\begin{tabular}{ccccccc}
\hline $\boldsymbol{w} / \boldsymbol{b}$ & Cement & $\begin{array}{c}\text { Silica } \\
\text { Fume }\end{array}$ & $\begin{array}{c}\text { Fine Quartz } \\
\text { Sand }\end{array}$ & $\begin{array}{c}\text { Coarse Quartz } \\
\text { Sand }\end{array}$ & $\begin{array}{c}\text { SP, by Mass } \\
\text { of Binder, } \%\end{array}$ & $\begin{array}{c}\text { Steel Fiber, by Volume } \\
\text { of Mixture, } \%\end{array}$ \\
\hline \multirow{3}{*}{0.18} & 1 & 0.3 & 0.22 & 0.88 & 1.4 & \\
& 1 & 0.3 & 0.22 & 0.88 & 1.6 & $0,1,2,3$ \\
& 1 & 0.3 & 0.22 & 0.88 & 1.8 & \\
\hline & 1 & 0.3 & 0.22 & 0.88 & 2 & $0,1,2,3$ \\
0.2 & 1 & 0.3 & 0.22 & 0.88 & 1.2 & \\
& 1 & 0.3 & 0.22 & 0.88 & 1.4 & \\
& 1 & 0.3 & 0.22 & 0.88 & 1.6 & \\
0.22 & 1 & 0.3 & 0.22 & 0.88 & 1.8 & \\
& 1 & 0.3 & 0.22 & 0.88 & 1 & \\
& 1 & 0.3 & 0.22 & 0.88 & 1.2 & \\
& 1 & 0.3 & 0.22 & 0.88 & 1.4 & \\
& 1 & 0.3 & 0.22 & 0.88 & 1.6 & $0,1,2,3$ \\
& 1 & 0.3 & 0.22 & 0.88 & 0.8 & 1 \\
\hline
\end{tabular}

\subsection{Mixing Procedure and Specimen Preparation}

Compared with normal strength concrete, the UHPC mixture in its fresh state is more sensitive to mixing procedures and environment. To minimize the influence of the operation process, all the mixtures were prepared by using a planetary mixer (Wuxi Jianyi Instrument \& Machinery Co., LTD, Wuxi, China) (as shown in Figure 2) using the same procedure. Dry ingredients, including cement, silica fume, and quartz sand, were first mixed for $3 \mathrm{~min}$ at a low speed of about $140 \pm 5 \mathrm{rpm}$. Then, water and superplasticizer were added and mixed for approximately $3 \mathrm{~min}$ at low speed. After, steel fibers (for mixes containing steel fibers) were uniformly added in the mixing pot and mixed for another $3 \mathrm{~min}$ at a high speed of about $285 \pm 10 \mathrm{rpm}$ until homogeneous mixtures were obtained. 


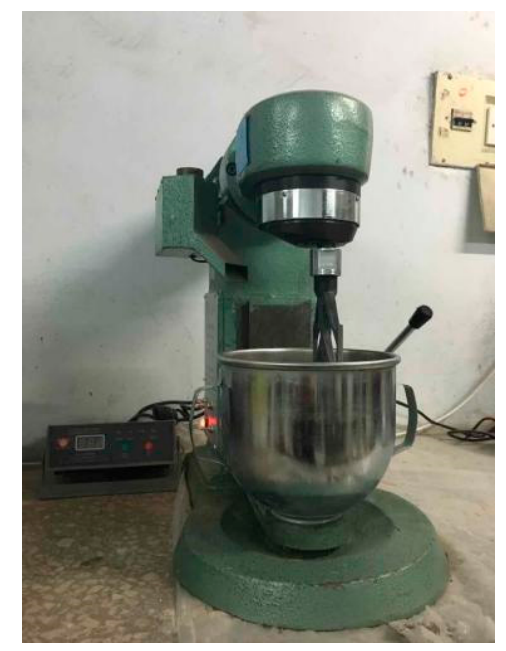

Figure 2. Mixer used for preparing ultra high performance concrete (UHPC).

When the UHPC mixtures were ready, prism specimens with a size of $40 \times 40 \times 160 \mathrm{~mm}^{3}$ were prepared by using a plastic mold (as shown in Figure 3). The mixture was cast in molds in two layers and vibrated for $90 \mathrm{~s}$ to consolidate the mixtures. The specimens in the molds were covered with plastic sheet and placed under room temperature $\left(22 \pm 3^{\circ} \mathrm{C}\right)$ for $24 \mathrm{~h}$ to minimize loss of water from the surface. Afterwards, the specimens were taken out from their molds and exposed to steam curing at $90^{\circ} \mathrm{C}$ for $72 \mathrm{~h}$. Finally, the specimens were stored in a standard curing room $\left(22 \pm 3^{\circ} \mathrm{C}, \mathrm{RH} 90 \%\right)$ until the time of mechanical measurements.

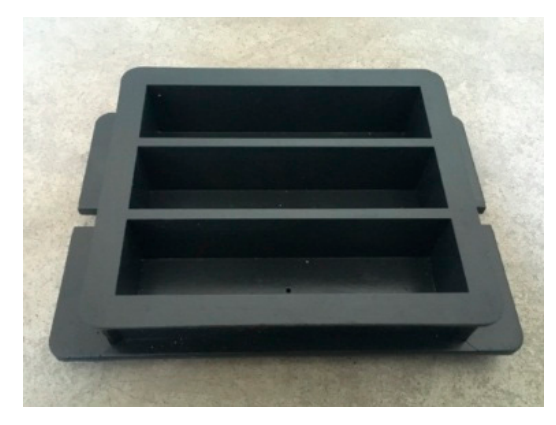

Figure 3. Plastic mold for prism specimens.

\subsection{Flowability and Air Content Test}

The flowability of all the fresh mixtures was carried out by using the test method for fluidity of cement mortar, in accordance with the Chinese National Standard GB/T 2419-2005 [19]. A mini cone mold was placed at the center of a jolting table, as shown in Figure 4. As soon as the mixing procedure was completed, the UHPC mixture was cast into the cone mold in two layers, and each layer is tamped 15 times with a tamping rod to fill the mixture uniformly in the mold. The mold was lifted vertically and the sample on the jolting table was dropped 25 times. Then, two diameters, perpendicular to each other, were determined and the mean value was recorded to evaluate the flowability. 


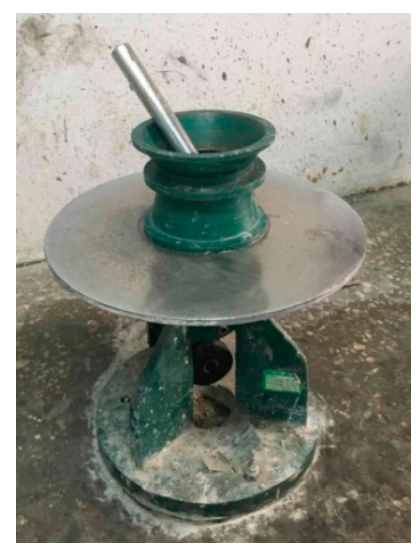

Figure 4. Test equipment for flowability.

The air content in fresh UHPC mixture was measured using the water column method, according to British standard EN 12350-7 [20], and the equipment (FORM + TEST Seidner \& Co. GmbH, Riedlingen, Germany) used is shown in Figure 5. The fresh UHPC mixture was poured into the cylinder container in two layers. Each was consolidated by a 15-fold drop on the table from a height of $30 \mathrm{~mm}$. After dropping, the upper part of the apparatus was applied to the lower container and measurement in a pressure apparatus was conducted. For every mixture, the air content was tested twice. If the difference between the two measured values was less than $0.2 \%$, the average value was determined as the test result. Conversely, if the difference between the two measured values was more than $0.2 \%$, the test result was invalid.

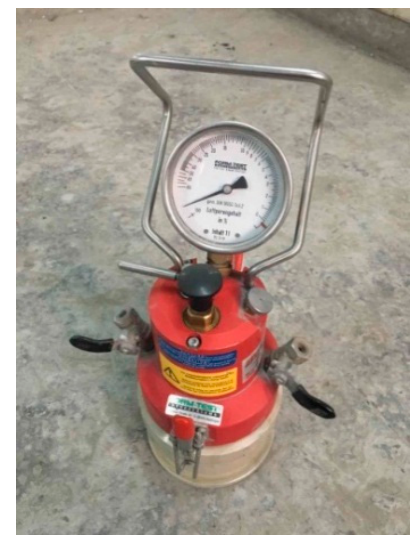

Figure 5. Measuring instrument for air content.

\subsection{Strength Measurement}

The compressive strength and flexural strength for every mixture were measured on the prepared prism specimens at 28 days of age, according to GB/T 17671-1999 [21]. A three-point flexural test was conducted, and averages of the three specimens for each batch were reported as tested results of flexural strength. Six broken samples, after the flexural test, were used to measure compressive strength with a loading rate of $1.5 \mathrm{kN} / \mathrm{s}$. The average of six samples for every mixture was reported as the tested compressive strengths. 


\section{Results and Discussion}

\subsection{The Flowability of Fresh Mixture}

Figure 6 presents the effects of steel fiber content, water-binder ratio and superplasticizer dosage on flowability of fresh UHPC mixtures. For all four different water-to-binder ratios, the flowability decreased with the increase of steel fiber content when the superplasticizer dosage was kept the same. The addition of $1 \%$ steel fiber led to a notable reduction of flowability when compared with the blank mixture without fiber, and a relatively slight decrease of flowability occurred when the addition of fiber increased from $1 \%$ to $3 \%$ for most of mixtures. For instance, the flowability of mixtures with $1 \%, 2 \%$, and $3 \%$ steel fibers were reduced by $22.3 \%, 25.8 \%$, and $28.8 \%$ compared to that of the blank mixture with a water-to-binder ratio of 0.20 , containing $1.4 \%$ superplasticizer. This flowability reduction effect might be attributed to the increased specific surface area of steel fiber [16], leading to an increased demand of cement paste for covering the surface of fibers and aggregates. On the other hand, the steel fibers were randomly distributed in the mortar matrix and acted as a skeleton, and eventually prevented the flow of fresh UHPC mixture [14].

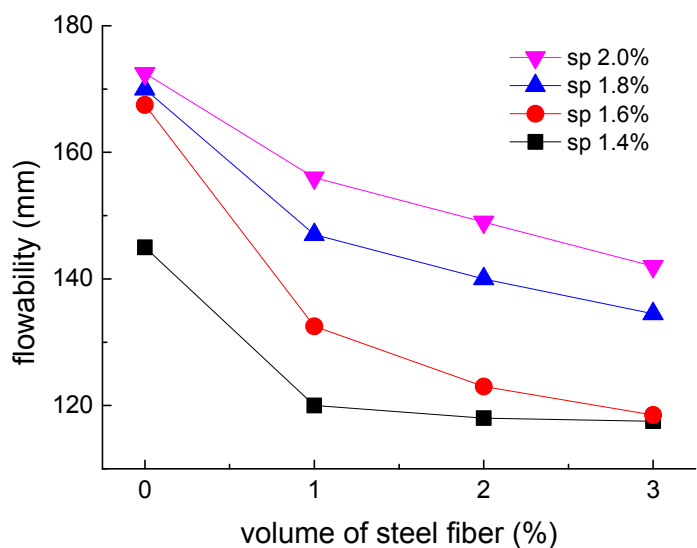

(a)

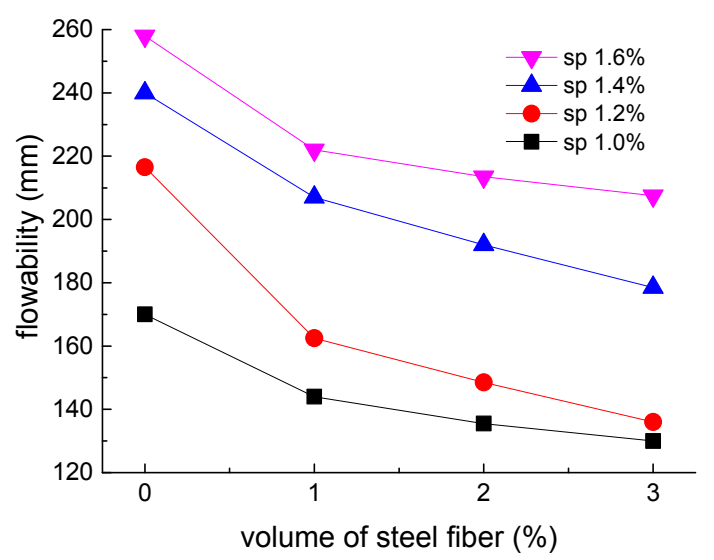

(c)

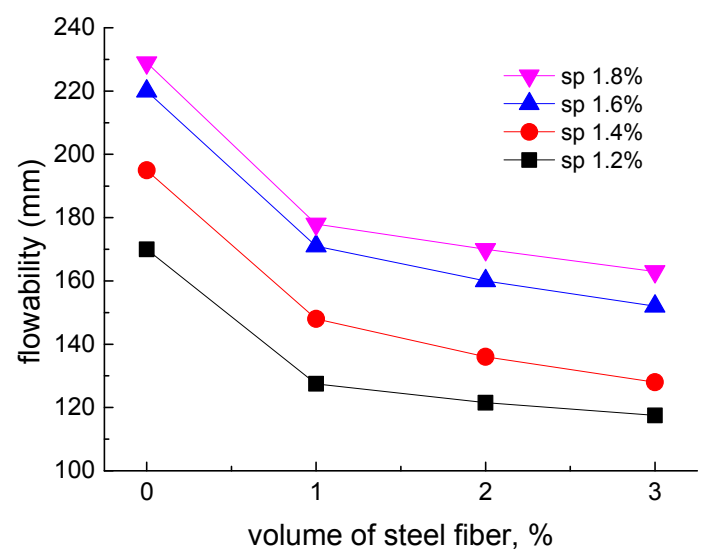

(b)

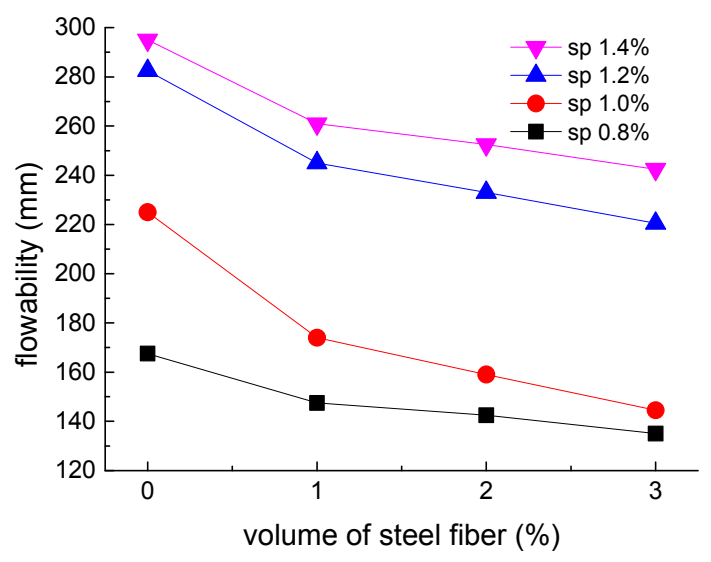

(d)

Figure 6. Effects of steel fiber content, water-binder ratio and superplasticizer dosage on flowability of fresh UHPC mixtures. (a) $w / b=0.18 ;(\mathbf{b}) w / b=0.20 ;$ (c) $w / b=0.22 ;$ (d) $w / b=0.24$.

When the same water-to-binder ratio and steel fiber content was used, the more dosage of superplasticizer increased the fluidity as expected. To increase the flowability, a higher dosage of superplasticizer was needed for UHPC mixtures with a lower water-to-binder ratio, due to a smaller amount of existing free water. For water-to-binder ratios of 0.24 and 0.22 , the flowability of the mixtures reached as high as $200 \mathrm{~mm}$ by using more superplasticizer, which is favorable for casting. However, 
for water-to-binder ratios of 0.18 and 0.20 , the increased dosage of superplasticizer led to a limited increase of flowability. Therefore, the fluidity was more sensitive to superplasticizer dosage in higher $w / b$ than in lower $w / b$ mixtures [22]. Such results reveal that a very low water-to-binder ratio may result in increased difficulty in compacting UHPC mixtures.

\subsection{The Entrapped Air in Fresh Mixture}

The test results of air content for all 64 UHPC mixtures are shown in Figure 7. It can be seen that most of the UHPC mixtures had $4 \%-6 \%$ air content, remarkably higher than that of normal concrete $(1 \%-2 \%)$, when no air entraining agent was used. The higher amount of entrapped air has a detrimental effect on the mechanical properties of UHPC, and special mixing technology to lower the air content has been developed [23]. Obviously, air content of a UHPC mixture decreased with the increase of steel fiber content, and the addition of $3 \%$ steel fiber led to about $0.9 \%-2.4 \%$ reduction of entrapped air content for different water-to-binder ratios. Such decreasing effects of steel fiber on air content were also found in the experiments of normal strength concretes [24]. The increasing air content in normal concrete was also reported by other researchers, being attributed to the difficulties of orientation and distribution of long fibers [25]. Therefore, the reduction effect of entrapped air content in UHPC mixtures can be explained by the good dispersion of short fibers when a high dosage of superplasticizer was used. Other possible reasons should be studied in future.

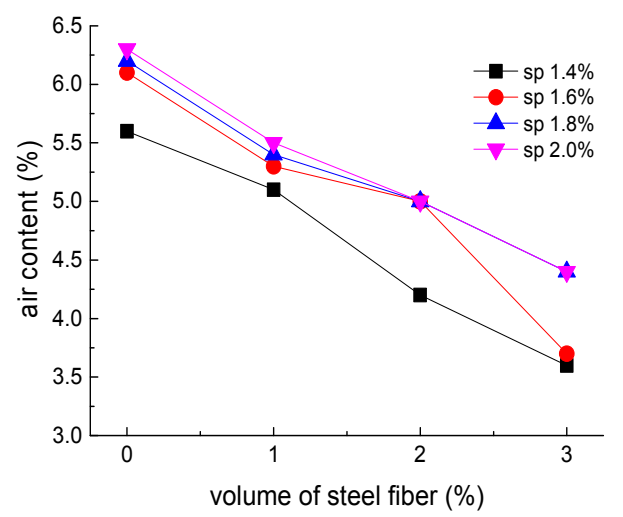

(a)

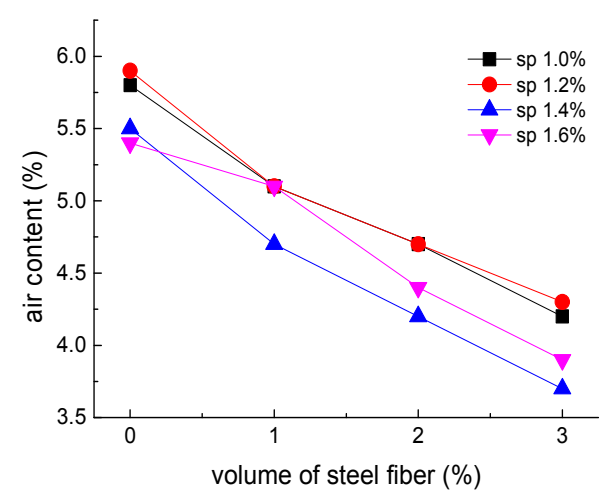

(c)

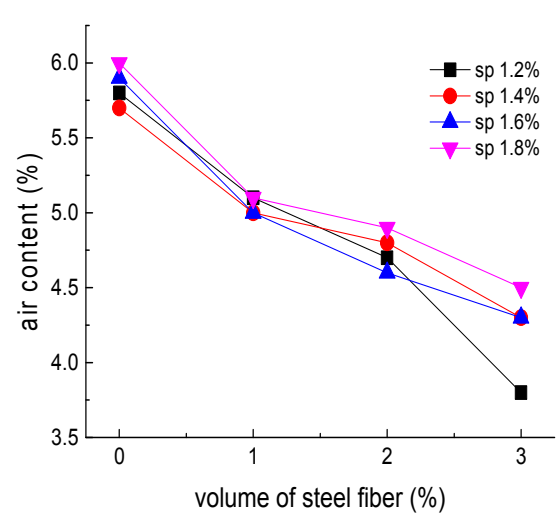

(b)

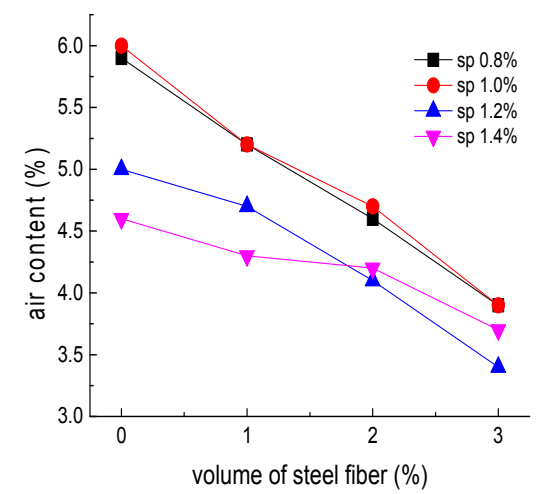

(d)

Figure 7. Effects of steel fiber content, water-binder ratio and superplasticizer dosage on air content of fresh UHPC mixtures. (a) $w / b=0.18 ;$ (b) $w / b=0.20 ;$ (c) $w / b=0.22 ;$ (d) $w / b=0.24$.

The influence of superplasticizer dosage on air content was related to water-to-binder ratio and the addition of steel fiber. The fluctuation range of air content decreased with lowering of the water-to-binder ratio. The influence of the water-binder ratio on the air content is not significant when a similar fluidity was obtained. 


\subsection{The Relationship between Flowability and Entrapped Air Content}

The relationship of flowability and entrapped air content of UHPC mixtures for every steel fiber addition is plotted in Figure 8. It can be seen that the air content generally decreased with the increase of flowability. It was believed that the nature of changes in air content for non-air-entrained concrete mixtures mainly depend on rheological parameters. Previous experiments showed that when yield stress and plastic viscosity decrease, the diameter of slump flow increases and time of slump flow decreases, and the air content in the SCC (Self Compacting Concrete) mixture also decreases [26]. This can be used to explain the tendency of change in entrapped air content with flowability for the UHPC mixtures in this study.

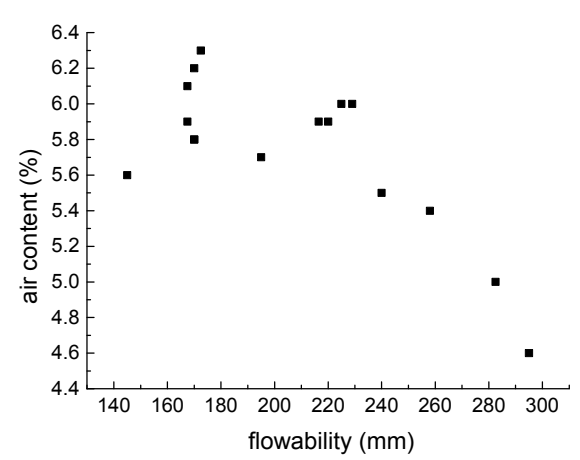

(a)

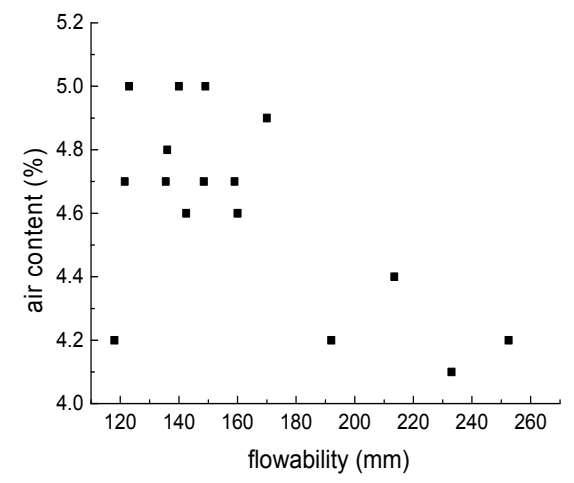

(c)

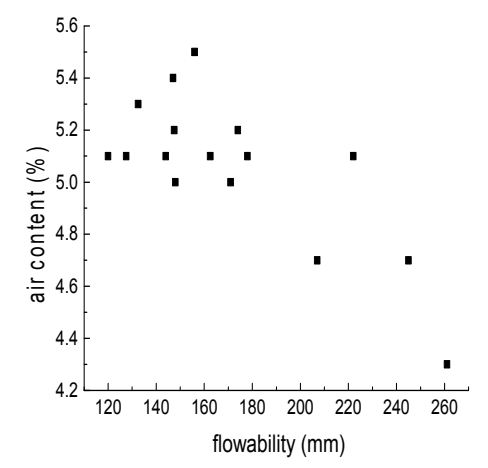

(b)

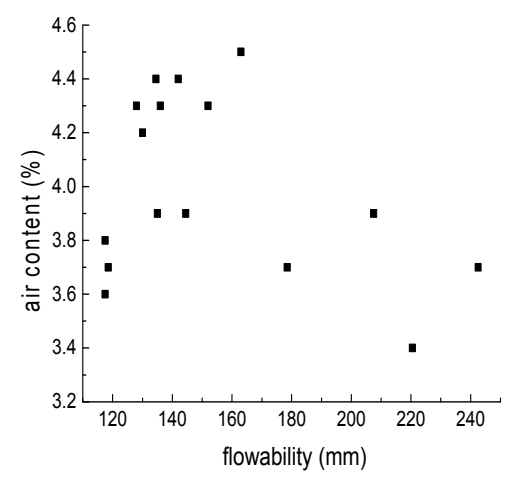

(d)

Figure 8. The relationship between the flowability and entrapped air content. (a) steel fiber $0 \%$; (b) steel fiber $1 \%$; (c) steel fiber $2 \%$; (d) steel fiber $3 \%$.

There was nearly a linear relationship between flowability and entrapped air content when no fiber was added. Additionally, this relationship became worse when a higher dosage of fiber was used. This is related to the influence of fiber on air content, and other possible reasons should be further investigated.

\subsection{Compressive and Flexural Strength}

\subsubsection{Compressive Strength}

Figure 9 shows the change in compressive strength of UHPC with different water-to-binder ratio, superplasticizer dosage, and steel fiber content. It can be seen that the compressive strength increased distinctly with higher fiber content for UHPC mixtures with the same water-to-binder ratio. When the fiber content increased from $0 \%$ to $3 \%$, the average increase of compressive strength for $0.18,0.20$, 0.22 , and 0.24 water-to-binder ratio mixtures were $59.1 \%, 53.9 \%, 49.8 \%$, and $38.9 \%$, respectively. As we know, increased steel fiber content could decrease the average space between fibers, which made 
more fibers sustain the load and leads to multi-cracks. Moreover, the addition of steel fiber delays the formation and propagation of cracks, and, thus, resulted in an increase of strength [14]. On the other hand, the increased strength might be directly related to the reduction of entrapped air content [23].

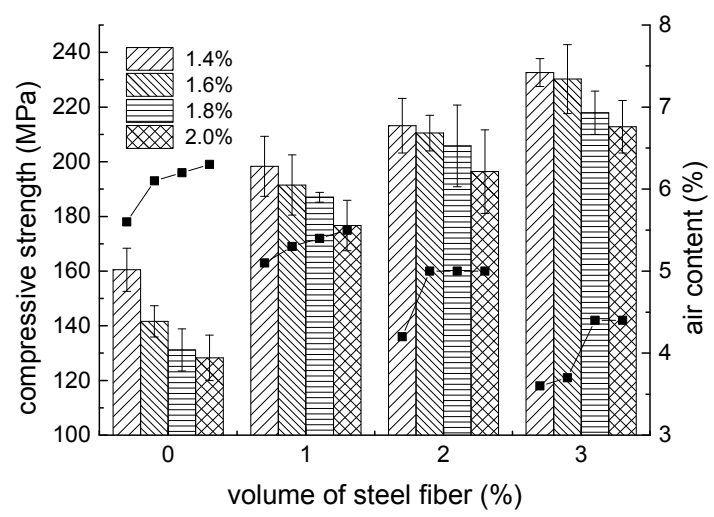

(a)

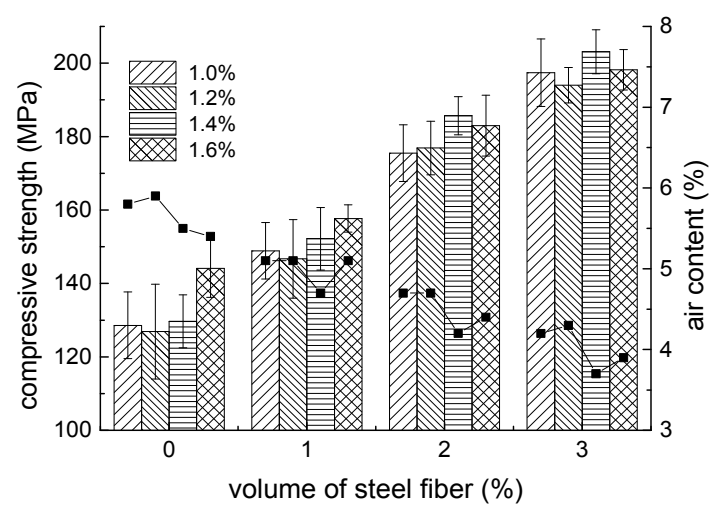

(c)

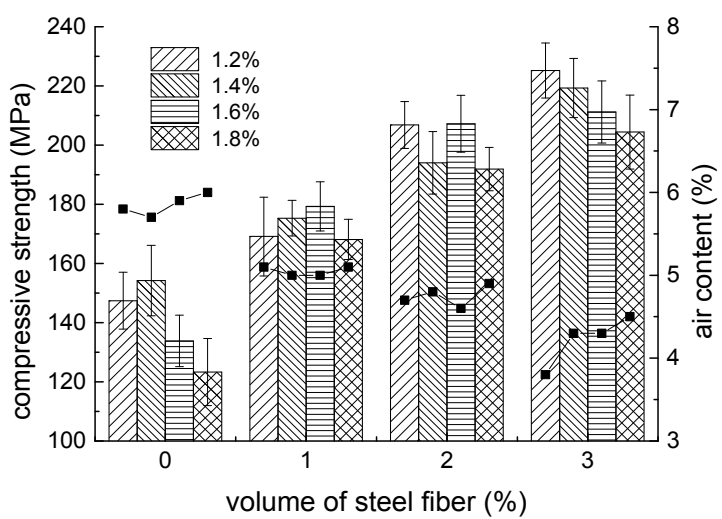

(b)

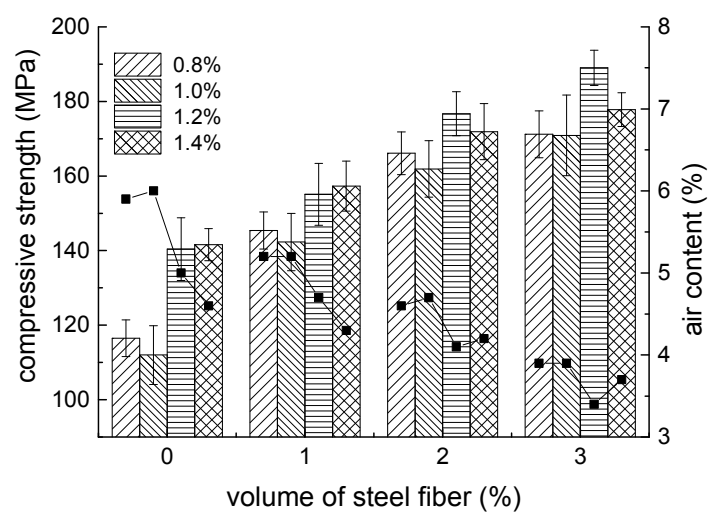

(d)

Figure 9. Compressive strength and air content of UHPC mixtures (column is strength and line is air content). (a) $w / b=0.18$; (b) $w / b=0.20$; (c) $w / b=0.22$; (d) $w / b=0.24$.

For the low water-to-binder ratio of 0.18 , a greater addition of superplasticizer reduced the compressive strength. For other water-to-binder ratios, the increase of superplasticizer dosage either increases or decreases the effect on compressive strength. For most of mixtures, the lower compressive strength could be attributed to the increase of entrapped air content in the fresh mixture.

The addition of steel fiber has a great influence on the failure mode of a UHPC specimen, as shown in Figure 10. The UHPC specimens without steel fiber have the typical characteristic of brittle failure under uniaxial compression. A loud noise occurred upon failure, and the specimen was completely crushed (small particle spalled). The addition of steel fiber increased the ductility of UHPC to some extent [3]. The specimen was almost intact after the compressive strength test, with only minor cracks on the surface and damaged particles connected by steel fibers. 


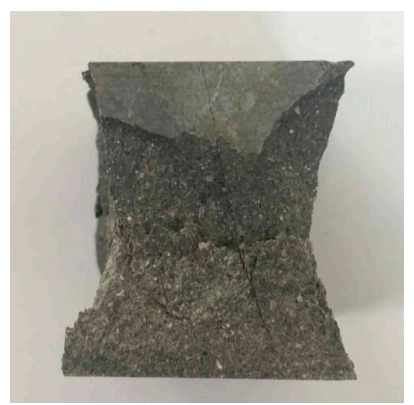

(a)

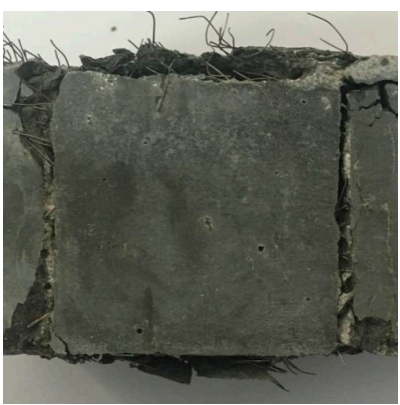

(b)

Figure 10. Failure appearance for UHPC specimen under uniaxial compression. (a) Plain specimen; (b) steel fiber reinforced specimen.

\subsubsection{Flexural Strength}

The flexural strength results for different UHPC mixtures are presented in Figure 11. When compared with the compressive strength, the addition of $1 \%$ steel fiber had a limited increase in flexural strength. In addition, the addition of $2 \%$ and $3 \%$ steel fiber provided a remarkable increase in flexural strength of about $24.9 \%-58.2 \%$ and $48.8 \%-88.7 \%$, respectively. This is attributed to the mechanical interlock and friction at the fiber-matrix interface, which suppressed the propagation and development of cracks. Furthermore, the higher addition of fiber provides more crack-bridging effects, thus, increasing the flexural load carrying capacity [24]. The variation in water-to-binder ratio and superplasticizer dosage had similar influences on flexural strength as that on compressive strength. For most of mixtures, less entrapped air content in the fresh state leads to an increased flexural strength of UHPC specimens, as expected.

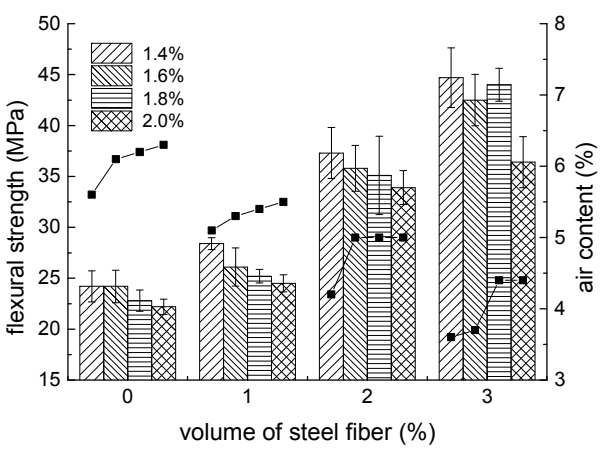

(a)

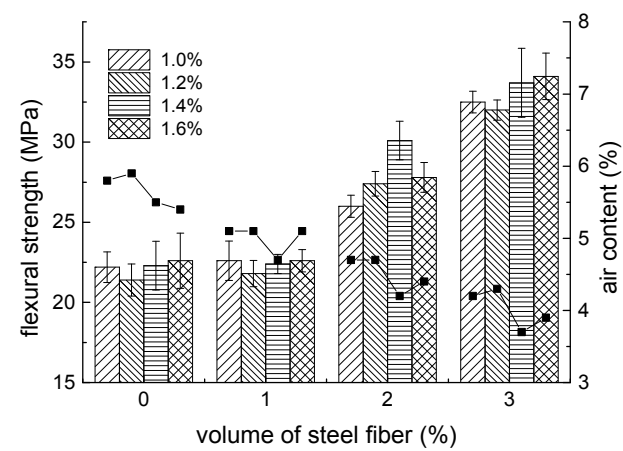

(c)

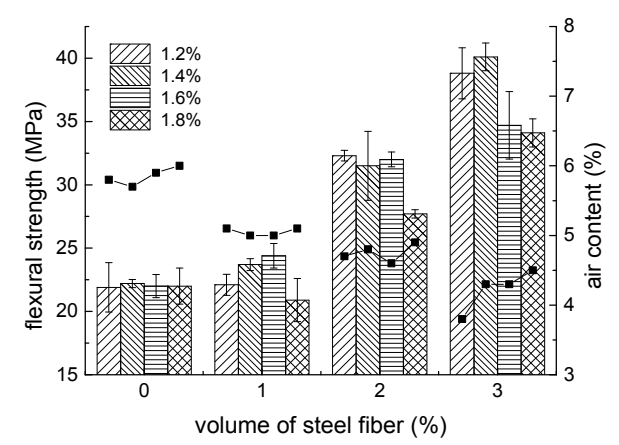

(b)

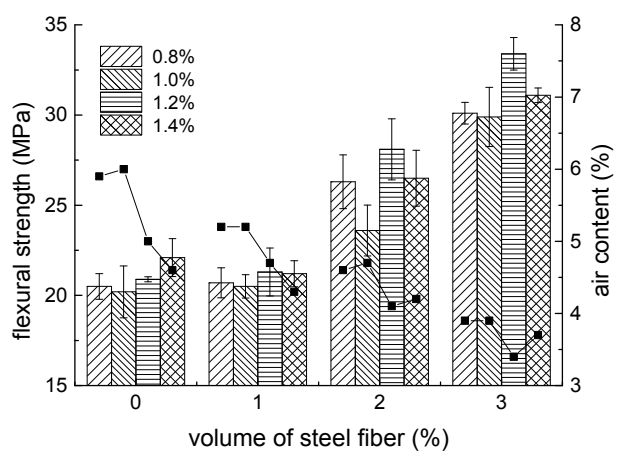

(d)

Figure 11. Flexural strength of UHPC mixtures (column is strength and line is air content). (a) $w / b=0.18 ;(\mathbf{b}) w / b=0.20 ;$ (c) $w / b=0.22 ;$ (d) $w / b=0.24$. 


\subsection{The Relationship between Compressive Strength and Entrapped Air Content}

At the same water-to-binder ratio, the relationship between compressive strength and air content of UHPC specimens, containing different dosages of steel fiber and superplasticizer, are plotted in Figure 12. It can be found that the compressive strength of UHPC increased linearly with the decrease of entrapped air content, regardless of the variable fiber content, ranging from $0 \%$ to $3 \%$. The regression equations are given in Figure 12a-d, where $F_{c}$ is the compressive strength $(\mathrm{MPa})$, and $A c$ is the air content (\%).

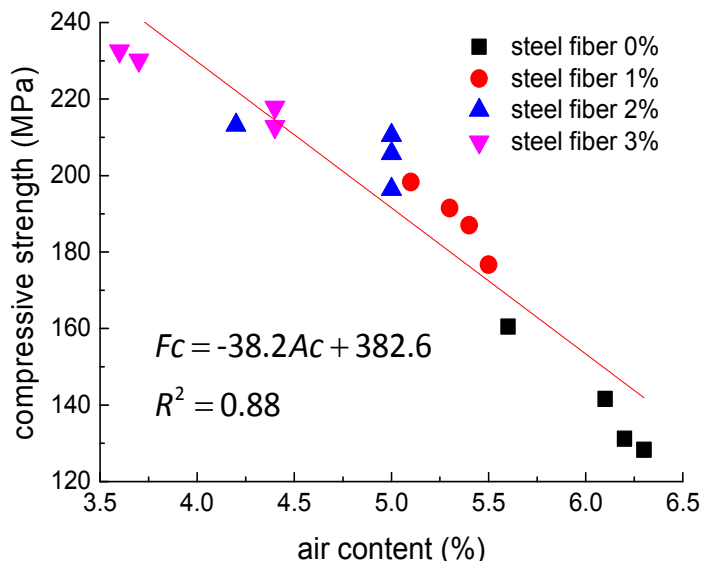

(a)

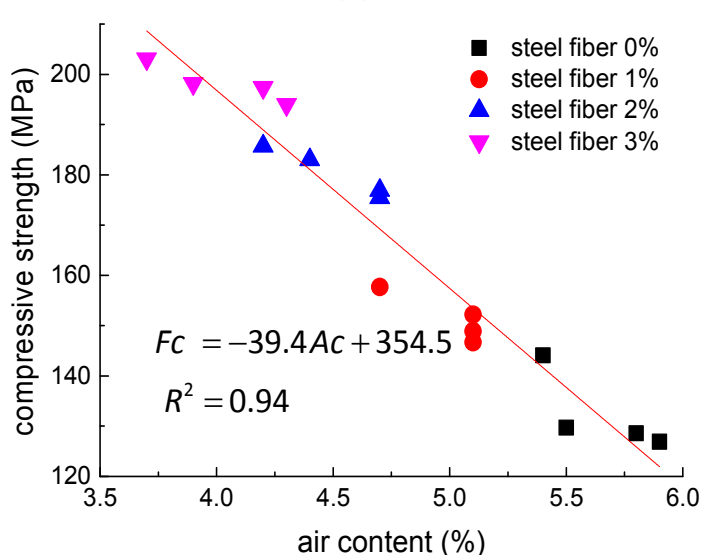

(c)

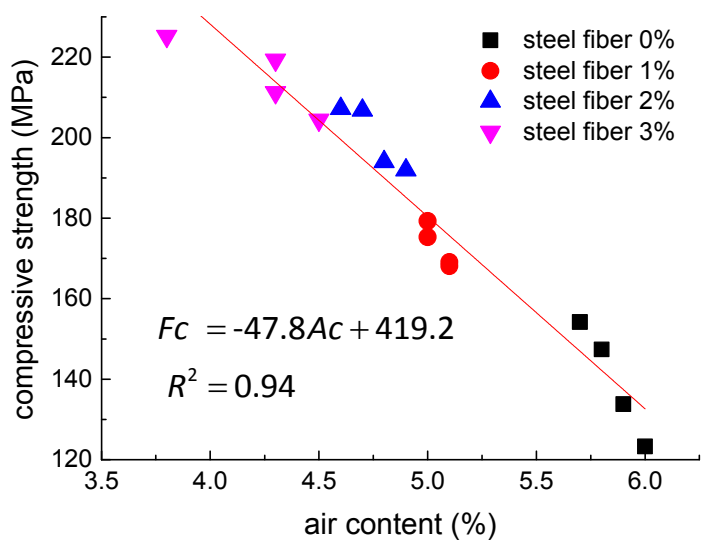

(b)

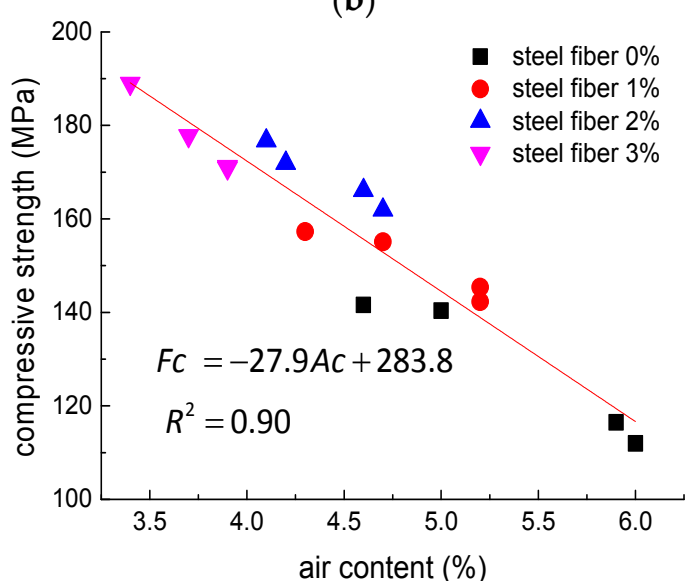

(d)

Figure 12. The relationship between the compressive strength and entrapped air content. (a) $w / b=0.18$; (b) $w / b=0.20 ;$ (c) $w / b=0.22 ;$ (d) $w / b=0.24$.

For normal-strength concrete, every $1 \%$ decrease in air content increases compressive strength of the concrete by $4 \%-6 \%$ [27], which is much lower than that found in UHPC specimens in this study. It was also mentioned that the air-void characteristics, such as size distribution, spacing (dispersion), and shape of air voids, have substantial effects on the mechanical properties of concrete [28]. Unfortunately, there is little information and experimental results available in the literature about this topic. Therefore, the variation in entrapped air structure may be another aspect for influencing the compressive strength of UHPC containing different dosages of steel fiber. Furthermore, the fact that the entrapped air content has a much higher influence on the compressive strength of UHPC than observed for normal concrete should be further investigated. 


\section{Conclusions}

(1) The addition of steel fiber decreased the flowability and entrapped air content of fresh UHPC mixtures. The fluidity was less sensitive for lower $w / b$ mixtures to superplasticizer dosage than that for higher $w / b$ mixtures. The influence of superplasticizer dosage on entrapped air content was related to the water-to-binder ratio and the addition of steel fiber.

(2) More addition of steel fiber (from 1\% to 3\%) led to an increasing compressive strength of UHPC specimens with different water-to-binder ratios and superplasticizer dosages. However, the addition of $1 \%$ steel fiber causes little increase in flexural strength, and the addition of $2 \%$ and $3 \%$ steel fiber provided a remarkable increase in flexural strength.

(3) To prepare flowable UHPC mixtures, a very high dosage of superplasticizer was added for lower water-to-binder ratios, which may have an adverse effect on strength gain. Additionally, the more addition of superplasticizer increased the strength of the UPHC mixtures with a higher water-to-binder ratio, due to the lower air content caused by the improved flowability.

(4) For the same water-to-binder ratio, there is a good linear relation between entrapped air content and compressive strength of UHPC specimens containing different dosages of steel fiber. Therefore, the decreasing effect on entrapped air content by the addition of steel fiber has a significant contribution to the improvement of the compressive strength of UPHC.

Acknowledgments: This work was supported by the National Natural Science Foundation of China (No. 51578192).

Author Contributions: Xiaojian Gao conceived and designed the experiments, and Rui Wang performed the experiments. Both of the authors analyzed the data and contributed to the writing of the paper.

Conflicts of Interest: The authors declare no conflict of interest.

\section{References}

1. Richard, P.; Cheyrezy, M. Composition of reactive powder concretes. Cem. Concr. Res. 1995, 25, $1501-1511$. [CrossRef]

2. Habel, K.; Viviani, M.; Denarie, E.; Bruhwiler, E. Development of the mechanical properties of an Ultra-High Performance Fiber Reinforced Concrete (UHPFRC). Cem. Concr. Res. 2006, 36, 1362-1370. [CrossRef]

3. Wang, D.; Shi, C.J.; Wu, Z.; Xiao, J.; Huang, Z.; Fang, Z. A review on ultra high performance concrete: Part II. Hydration, microstructure and properties. Constr. Build. Mater. 2015, 96, 368-377. [CrossRef]

4. Alkaysi, M.; El-Tawil, S.; Liu, Z.; Hansen, W. Effects of silica powder and cement type on durability of ultra high performance concrete (UHPC). Cem. Concr. Comp. 2016, 66, 47-56. [CrossRef]

5. Shi, C.J.; Wu, Z.; Xiao, J.; Wang, D.; Huang, Z.; Fang, Z. A review on ultra high performance concrete: Part I. Raw materials and mixture design. Constr. Build. Mater. 2015, 101, 741-751. [CrossRef]

6. Shi, C.J.; Wang, D.H.; Wu, L.M.; Wu, Z.M. The hydration and microstructure of ultra high-strength concrete with cement-silica fume-slag binder. Cem. Concr. Compos. 2015, 61, 44-52. [CrossRef]

7. Yu, R.; Spiesz, P.; Brouwers, H.J.H. Development of an eco-friendly Ultra-High Performance Concrete (UHPC) with efficient cement and mineral admixtures uses. Cem. Concr. Compos. 2015, 55, 383-394. [CrossRef]

8. Tafraoui, A.; Escadeillas, G.; Lebaili, S.; Vidal, T. Metakaolin in the formulation of UHPC. Constr. Build. Mater. 2009, 23, 669-674. [CrossRef]

9. Van Tuan, N.; Ye, G.; Van Breugel, K.; Copuroglu, O. Hydration and microstructure of ultra high performance concrete incorporating rice husk ash. Cem. Concr. Res. 2011, 41, 1104-1111. [CrossRef]

10. Park, J.S.; Kim, Y.J.; Cho, J.R.; Jeon, S.J. Early-Age Strength of Ultra-High Performance Concrete in Various Curing Conditions. Materials 2015, 8, 5537-5553. [CrossRef]

11. Wille, K.; Naaman, A.; El-Tawil, S.; Parra-Montesinos, G. Ultra-high performance concrete and fiber reinforced concrete: Achieving strength and ductility without heat curing. Mater. Struct. 2012, 45, 309-324. [CrossRef]

12. Kang, S.-T.; Lee, Y.; Park, Y.-D.; Kim, J.-K. Tensile fracture properties of an Ultra High Performance Fiber Reinforced Concrete (UHPFRC) with steel fiber. Compos. Struct. 2010, 92, 61-71. [CrossRef] 
13. Abbas, S.; Soliman, A.M.; Nehdi, M.L. Exploring mechanical and durability properties of ultra-high performance concrete incorporating various steel fiber lengths and dosages. Constr. Build. Mater. 2015, 75, 429-441. [CrossRef]

14. Wu, Z.M.; Shi, C.J.; He, W.; Wu, L.M. Effects of steel fiber content and shape on mechanical properties of ultra high performance concrete. Constr. Build. Mater. 2016, 103, 8-14. [CrossRef]

15. Kang, S.T.; Lee, B.Y.; Kim, J.K.; Kim, Y.Y. The effect of fibre distribution characteristics on the flexural strength of steel fibre-reinforced ultra high strength concrete. Construct. Build. Mater. 2011, 25, 2450-2457. [CrossRef]

16. Yu, R.; Spiesz, P.; Brouwers, H.J.H. Mix design and properties assessment of ultra-high performance fibre reinforced concrete (UHPFRC). Cem. Concr. Res. 2014, 56, 29-39. [CrossRef]

17. Chinese National Standard. Common Portland Cement; Chinese National Standard: Beijing, China, 2007; GB175-2007.

18. Chinese National Standard. Silica Fume from Electric-furnace; Chinese National Standard: Beijing, China, 2007; GB/T 21236-2007.

19. Chinese National Standard. Test Method for Fluidity of Cement Mortar; Chinese National Standard: Beijing, China, 2005; GB/T 2419-2005.

20. British Standard. Testing Fresh Concrete; British Standard: London, UK, 2009; EN 12350-7:2009.

21. Chinese National Standard. Method of Testing Cements-Determination of Strength; Chinese National Standard: Beijing, China, 1999; GB/T 17671-1999.

22. Yamada, K.; Takahashi, T.; Hanehara, S.; Matsuhisa, M. Effects of the chemical structure on the properties of polycarboxylate-type superplasticizer. Cem. Concr. Res. 2000, 30, 197-207. [CrossRef]

23. Dils, J.; Boel, V.; Schutter, G.D. Vacuum mixing technology to improve the mechanical properties of ultra-high performance concrete. Mater. Struct. 2015, 48, 3485-3501. [CrossRef]

24. Balaguru, P.; Ramakrishnan, V. Properties of Fiber Reinforced Concrete: Workability, Behavior under Long-Term Loading, and Air-Void Characteristics. ACI Mater. J. 1988, 85, 189-196.

25. Uygunoğlu, T. Effect of fiber type and content on bleeding of steel fiber reinforced concrete. Constr. Build. Mater. 2011, 25, 766-772. [CrossRef]

26. Kostrzanowska-Siedlarz, A.; Gołaszewski, J. Rheological properties and the air content in fresh concrete for self compacting high performance concrete. Constr. Build. Mater. 2015, 94, 555-564. [CrossRef]

27. Mehta, P.K.; Monteiro, P.J.M. Concrete: Microstructure, Properties, and Materials, 3rd ed.; McGraw-Hill: New York, NY, USA, 2006.

28. Choi, P.; Yeon, J.H.; Yun, K.K. Air-void structure, strength, and permeability of wet-mix shotcrete before and after shotcreting operation: The influences of silica fume and air-entraining agent. Cem. Concr. Comp. 2016, 70, 69-77. [CrossRef]

(C) 2016 by the authors; licensee MDPI, Basel, Switzerland. This article is an open access article distributed under the terms and conditions of the Creative Commons Attribution (CC-BY) license (http://creativecommons.org/licenses/by/4.0/). 